\title{
The impact of supply chain partnership and market driven strategy on consumer behavior in buying Vocaloid Hatsune Miku products
}

\author{
Vicio Rizky Damar ${ }^{1, *}$, Markus Hartono ${ }^{1}$ \\ ${ }^{1}$ Postgraduate Program in Logistics and Supply Chain Engineering, University of Surabaya, 60293 \\ Surabaya, Indonesia
}

\begin{abstract}
Hatsune Miku is the first virtual singer who is currently achieving success, even up to the world level. Miku has a large number of fansbase, like a famous singer. Its popularity also helps Crypton Future Media, as the company maker of Miku, to collaborate, forming a supply chain partnership with several big companies, to bring Miku into real products, which fans can have. This literature review explores this literature study explores Miku's development ever since it was created, until it became famous, and gave rise to a unique supply chain partnership. Researcher using systematic literature review method, with the aim of understanding how big the impact of Supply Chain Partnership and Market Driven from the success of virtual singer Hatsune Miku to consumer behavior, both from the general public and fans. The impact of this unique supply chain partnership is to make consumers loyal and feel close.
\end{abstract}

\section{Introduction}

Rapid technological developments bring new innovations. The emergence of these innovations starting from the internet, mobile phones that turn into smartphones, even social networks like Facebook or Youtube. However, there is one rare phenomenon that is currently being experienced throughout the world, namely the birth of a singer who is not a human being. Hatsune Miku can be regarded as the latest innovation. Miku is the first android idol figure of a hologram that successfully sold more than a million. Her fans wrote songs for him and created a style for her. Its popularity is increasing after Hatsune Miku concert held in various places in the world [1].

Hatsune Miku is a virtual singer from a vocaloid program, a software that produces the sound of human singing. She debuted in 2007, at Nico-Nico Douga Network, gained a positive response and great enthusiasm from Japanese music lovers. The presence of Hatsune Miku today, even able to rival the popularity of real singers. This is because she has a huge

\footnotetext{
${ }^{*}$ Corresponding author: viciorizky@yahoo.com
} 
fan base around the world, there are even separate communities. Even in his own country, Miku is already considered a national identity of Japan [2].

Hatsune Miku's own success in the eyes of the world is not just the result of the creator's creation, Crypton Future Media, but much of the fans' support contributed greatly, and the creativity of communities created songs containing Miku's voice [3]. The birth of virtual singers such as Hatsune Miku spawned new products associated with it, especially in terms of merchandise, album or single track. The company owner of Miku, Crypton Future Media, collaborated from well-known composers in Japan, to several big companies to give birth to Miku in the form of real, and can be owned by fans.



Fig. 1.: Character Design of Hatsune Miku (source: Crypton's official image of Hatsune Miku)

The purpose of this study is to understand how big the impact of Supply Chain Partnership and Market Driven from the success of Hatsune Miku virtual singer to consumer behavior, both from the general public and fans. This literature review based from literature and news that has been there before.

Supply chain partnerships can be defined as relationships between different companies, which have compatible strategic objectives, and resources and capabilities. These compatible aspects include management and operations, trust and high-commitment organizational structures, information sharing and risk, to meet common goals, which are key to supply chain management [4]. Partnership is mostly done between Crypton Future Media and big companies in Japan or the world, to realize Hatsune Miku, which is a virtual singer into real products, and also be involved in advertising.

G.S. Day defines organizations as market-driven if they implement customer value centered strategies, and supported by market orientation, to develop new innovations. In addition, there has been intense competition due to the opening of new markets, and is characterized by new players with increasingly sophisticated strategies [5].

In this study, collaboration between Crypton and other companies not only market the product, but indirectly contributed to increase Miku's popularity. Crypton's market driven performs this unique collaboration, raising market and customer value. Customers, remain loyal to follow Miku's development, and buy products intensely, and create new markets in Japanese music world.

\section{Literature Review}

\subsection{Supply Chain Partnership}

Today, many companies are realizing the importance of supply chain partnerships, and are beginning to implement them. Partnership is a temporary relationship between corporate partners, which can lead to further relationships due to trust, and exchange or sharing information [6]. This theory was later supported by Longren's research, which mentions the 
success factors of supply chain partnership is decentralized task management, application of information technology, and mutual trust [7].

\subsection{Market Driven}

The development of technology led to companies or organizations that are now oriented to market driven. Day's research argues that a market driven organization, has set a high priority on value creation, for both consumers and potential customers. Companies or market driven oriented organizations, will be demanded innovatively, and create strategies that will win global competition [8].

Crypton to create a new market driven, with virtual singers like Miku as a new commodity and brand image. Crypton teamed up with composers and creators to create new song and costumes suited to Miku, and took big companies to keep relationships with consumers, while gaining huge commercial value by trying to capture potential customers. It is considered unique, and can hit the traditional values of media mix in Japan [9].

\subsection{Vocaloid and History of Hatsune Miku}

Vocaloid (ボーカロイド) is a Yamaha Corporation production software that produces the sound of human singing. Music compositions and lyrics are inserted on the editors screen according to the desired singing and music accompaniment. The singing sound is taken from the "sound library" which contains the sampling of sound recording from the real singer. Song lyrics are sung in English, Korean or Japanese [10]. Hatsune Miku, which was the production of Crypton Future Media company in 2007. Miku is Crypton's second project vocaloid. Miku's voice sampling was taken from Saki Fujita's voice. Miku then debuted at Nico-Nico Douga Network. In its development, Hatsune Miku, originally produced only in Japanese voices, began to be Korean, Mandarin, and English. It aims to meet the interests of consumers around the world. On September 12, 2007, Amazon Japan released Hatsune Miku sales report of 57.5 million yen. July 2008, sales totaled 40,000 units, with sales per week on average reaching 300 units. In January 2011, sales reached 60,000 units.

In addition, in 2010, Hatsune Miku got the addition of a sound version, known as the Hatsune Miku Append. What distinguishes is on Hatsune Miku Append, there are 6 tones sound different from the sound of Miku at first. Tones are like Soft, dark, sweet, vivid, solid, and light. There is a fundamental difference between the six tones, which is located from the tempo and the tone. [11]

\subsection{Supply Chain Partnership Crypton with Other Companies}

Crypton Future Media, as the owner of Hatsune Miku products, works with major Japanese companies to collaborate on making Hatsune Miku products. Hideki's research mentioned that the action figures, Album CD or Single, and Games, became a real contribution to the Hatsune Miku market, and meet the fans' needs. In addition, concert related needs are also held by Crypton to meet the fans' wishes. Some companies that collaborate such as Good Smile Company, Sony Entertainment, Sega, etc [12]. 


\subsubsection{Partnership Crypton with Good Smile Company}

Crypton working with Good Smile Company produces more than 15 types of Hatsune Miku action figures, and has sold over 100,000 units. In addition, Good Smile and Crypton create a special branding titled "Good Smile Racing Miku" which began in 2008 until now, with a variety of designs [13]. In addition, the two companies also created a Miku's action figure to welcome the winter festival, which is held annually in Sapporo since 2010.

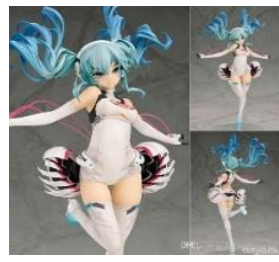

Fig. 2: Action Figure Hatsune Miku (source: Good Smile Company's official website)

\subsubsection{Partnership Crypton With Sega and Sony Entertainment}

Le said that the role of Hatsune Miku gives great success to Sega. Collaboration between Crypton Future Media with SEGA currently spawned a game called Hatsune Miku: Project Diva. This game was released on July 2nd, 2009 with the same title. Music sources and illustrations from Project Diva itself include difficult to distinguish from other games. This is because the song itself comes from the Hatsune Miku community, which has been criticized, evaluated, and has popularity, before being taken by Sega. For marketing and consoles used, Crypton teamed up with Sony Entertainment, the company owner of popular game consoles like Playstation Portable (PSP), Playstation Vita (PS Vita), Playstation 3 and Playstation 4 [14]. Project Diva contributes greatly to Sony Entertainment's own market share. Nunneley (2012) gives an example that Game Project Diva F becomes number one, with sales reaching 159,592 units, and help PS Vita to win the competition with its competitors [15].

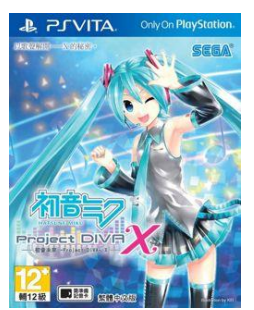

Fig. 3: Game Project Diva

\subsubsection{Partnership Crypton with Sony Mobile Communications}

Sony released the Xperia SO-04E, with the bundle Hatsune Miku Limited edition, with a special model in the theme that has been installed in the handset, as well as content such as wallpapers and special music widgets to listen to songs Hatsune Miku [16]. On 2016, Sony called Miku again to promote Xperia X Series Smartphone. The reason Sony chose Hatsune Miku because this character is a very popular virtual idol, and is known outside of Japan. [17]. 


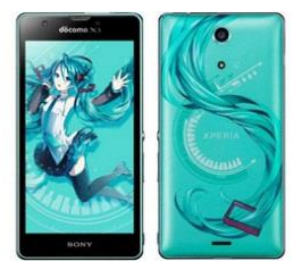

Fig. 4. Sony Xperia SO-04E Hatsune Miku Limited Edition

\subsection{Miku's Popularity As a Brand Ambassador}

The popularity of Hatsune Miku around the world, responded by a number of big companies to make it an advertising star. One of Japan's largest automotive companies, Toyota, helped make Hatsune Miku as a brand ambassador. Hatsune Miku became the advertising star for their product, Toyota Corolla, in an effort to expand into the US automotive market. That collaboration won the Multicultural Excellence Award from the ANA Multicultural Marketing \& Diversity Conference In addition to aiming at market development, Toyota helped Miku to debut in the United States [18]. Another unique collaboration takes place in the field of beauty products. Renowned beauty products in the world, Lux, took Hatsune Miku and American actress, Scarlett Johansson, to introduce new shampo products [19].

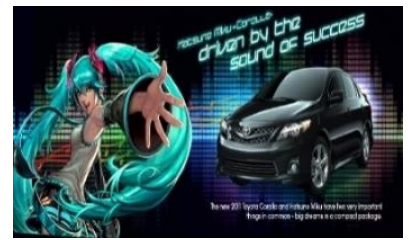

Fig. 5: Toyota Corolla ads collaborate with Hatsune Miku

\subsection{Hatsune Miku's Concert and Famous Songs}

Crypton Future Media held a Hatsune Miku concert called "Hatsune Miku Expo" since 2009, and has been going on in several countries, such as China, Los Angeles, New York, etc. Miku's first concert, MikuFes, featured famous composers in Japan. Hatsune Miku was also introduced first in the form of holograms. In Indonesia, Miku Expo held in Jakarta, 28-29 May 2014. That concert according to research conducted Putra is considered expensive. This is based on observations and interviews to the Vocaloid community in East Java. In addition, fans from outside Jakarta could not go to the concert, due to limited accommodation. Miku concert ticket price itself is in the range Rp 390.000-Rp 1.390.000,- [20].

There are many songs and CDs that made famous composers with Hatsune Miku as a singer. For example is a CD entitled "EXIT TUNES PRESENTS Vocalogenesis feat. Hatsune Miku" was released May 19, 2010, and topped the Oricon Chart. In the USA, Amazon launched one of the singles from Supercell's Album, World is Mine, set up on May 7, 2011, earning the position of 7 of the top 10 world singles sold on iTunes in the first week of release. He (2014) also exemplifies the case of the Black Rock Shooter song, made by Supercell, by sampling Miku's voice. Combined with the character of Black Rock Shooter itself illustrated by Huke, this song became very popular in Japan. Then, Black Rock Shooter became a franchise, and adapted into anime, games, even manga. [21] 


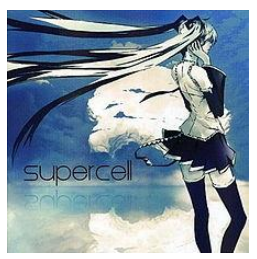

Fig. 6: Hatsune Miku songs and CDs (source: vocaloid wikia)

\subsection{Factors Influence Consumer Behavior Against Miku Popularity}

Kotler and Keller mentioned there are four factors that influence consumer behavior. These factors are cultural, social, personal, and psychological factors [22]. Culture according to Schifmann and Kanuk can be used as a determinant of the most basic desires and behaviors [23]. The second is the social factor, that divided into reference groups, families, and social roles and status. Primary groups such as family, friends, neighbors, and colleagues who interact regularly and informally. Secondary groups, such as denominations, professions, and trade associations, tend to be formal and require no regular interaction [22]. Last is personal factors and psychological factors. This personal characteristic is also closely related to the psychological factors of the consumer. There are four psychological factors according to that affect the purchase, such as motivation, perception, knowledge, and beliefs and attitudes [24].

Hatsune Miku's popularity in the world, including in Indonesia, is supported by popular Japanese culture, which likes anime and manga, J-pop, and virtual idols. The role of community and fansbase has a big power to support Miku [11]. Fans and her community have a high level of enthusiasm, because they want to keep up to date with the development of the Vocaloid world, especially Hatsune Miku. They also do consumption activities, such as buying action figures, buying CDs, attending concerts, etc., so they can be satisfied [25].

\section{Development of Framework Related to Supply Chain Partnership and Market Driven Impact on Consumer Behavior of Hatsune Miku Products}

This literature review explores this literature study explores Miku's development ever since it was created, until it became famous, and gave rise to a unique supply chain partnership. Researcher using systematic literature review method. Researchers not only take from miku related papers, but also from news related to her popularity and colaboration between Crypton and other companies.

One such successful collaboration is related to the sale of Hatsune Miku Project Diva game that helped Playstation achieve success, and liked the fans. This success then spawned the next series of Project Diva games routinely by Sega and Sony. Another successful collaboration between Miku and Toyota. Despite its success, Le's research considers Toyota's marketing strategy less effective, because Toyota failed to target fans, and has been heavily criticized by fans regarding the design of ad posters. Researchers considered Le's study to be a contrast, which, although Le considers the collaboration between Toyota and Crypton is a mistake, but researchers see the error is precisely the first step in Miku's success in the USA. This also applies in contrast when Putra's research related to the Miku concert in Indonesia is considered to be some expensive fans. Researcher consider the findings did not dampen the enthusiasm of fans, supported by research data from Rahmawati's research. 
From the overall theory and the literature that has been obtained, then formed a framework that can explain the impact of supply chain partnership and market driven to consumer behavior of Hatsune Miku products as follows:

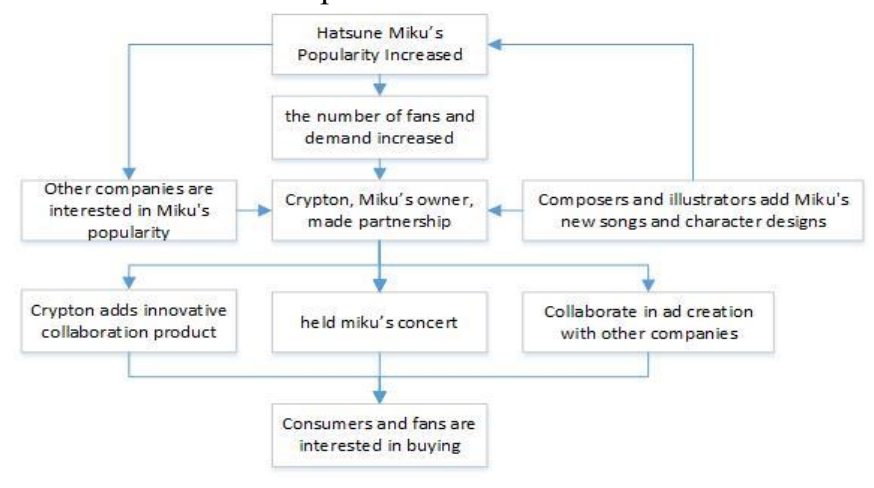

Fig. 7: Framework Related to Supply Chain Partnership and Market Driven Impact on Consumer Behavior of Hatsune Miku Products

In supply chain partnership, variables related to product innovation between Crypton and other companies become variables that influence consumer behavior. It also serves as the company's foundation for determining market driven strategies. The main variables in market driven that greatly affect consumer behavior, is related to customer orientation and service and customer sastifaction.

\section{Conclusion}

The conclusion that can be drawn from this research is with the popularity of virtual singers like Hatsune Miku, Crypton company take steps partnership with other companies to be able to meet consumer demand. The partnership step is also taken to make fans feel close to Hatsune Miku. Other companies working closely with Crypton have a big impact, like make huge profits and sales, or exclusive and limited branded product.

From all this collaboration, it can be concluded that this collaboration accentuated the popular Japanese culture factor, which on average liked anime, manga, J-pop, and Virtual Idol. In addition, social factors, such as the Miku's fans community, play a major role in influencing consumer behavior decisions. The enthusiasm side of Miku fans, taking on the emotional side of fans, is considered an irrational motivation. All these factors then make the consumer loyal. In addition, in this research, product innovation, customer orientation, and service and customer sastifaction are considered as influential variables to see how big the impact of supply chain partnership and market driven on consumer behavior.

In this research, the suggestion that can be submitted is the further research that can be developed related to the business of Hatsune Miku related products, which is quantitative, to be able to measure more accurately, validly and reliably how big the impact of supply chain partnership and market driven to consumer behavior can have a big effect or not. 


\section{References}

1. Y. Linggasari, Hatsune Miku, Penyanyi Vocaloid yang Mulai Mendunia, http://www.cnnindonesia.com/hiburan/20141208090651-227-16454/hatsune-mikupenyanyi-vocaloid-yang-mulai-mendunia , (2014)

2. C. Wicoff, CJAS, 2 (2013)

3. R. Eisenbeis, Why Hatsune Miku is the World's Most Popular Virtual Idol. https://kotaku.com/5936200/why-hatsune-miku-is-the-worlds-most-popular-virtualidol , (2012)

4. W. Han, SS, $4(2014)$

5. G.S. Day, JM, 58, 37 (1994)

6. D.A. Johnston, D.M. Mccutheon, F.I. Stuart, H. Kerwood, JOM, 22, 525 (2004)

7. H.M. Lönngren, C. Rosenkranz, H. Kolbe, SCM, 15, 404 (2010)

8. G.S. Day, CMR, (1994)

9. P.W. Galbraith, J.G. Karlin, Media Convergence in Japan (Kinema Club, 2016)

10. H. Kenmochi, H. Oshita, ISCA (2007)

11. Y. Rahmawati, Wahana, 1 (2016)

12. H. Kenmochi, ISCA (2010)

13. B.A. Mesquita, $U F R J(2016)$

14. L.K. Le, UCI URJ, 17 (2013)

15. S. Nunneley, Vita tops in Japan thanks to Hatsune Miku Project Diva $f$, http://www.vg247.com/2012/09/05/vita-tops-hardware-in-japan-thanks-to-hatsunemiku-project-diva-f-release/ (2012)

16. Selular.id, Hatsune Miku, Sony Xperia A Limited Edition dari NTT Docomo, $\mathrm{http}: / /$ selular.id/2014/10/hatsune-miku-sony-xperia-a-limited-edition-dari-ntt-docomo/ (2014)

17. Nariswari, Sony Gandeng Hatsune Miku Promosikan Xperia. https://www.tabloidpulsa.co.id/news/25634-sony-gandeng-hatsune-miku-promosikanxperia , (2016)

18. A. Dumitrache, 2011, Toyota Corolla Introduces Hatsune Miku to the US. https://www.autoevolution.com/news/2011-toyota-corolla-introduces-hatsune-mikuto-the-us-video-35258.html (2011)

19. B. Aschraft. Hatsune Miku And Her Virtual Hair Are Selling Shampoo In Japan, https://kotaku.com/hatsune-miku-and-her-virtual-hair-are-selling-shampoo-i1785882599 (2016)

20. A.S. Putra, Repository Unair (2017)

21. T. He, AJCL, 62, 1009, (2014)

22. P. Kotler, K.L. Keller, Manajemen Pemasaran (PT Indeks, 2009)

23. L. Schiffman, L.L. Kanuk, Perilaku Konsumen (PT Indeks, 2008)

24. A. Thamrin, F. Tantri, Manajemen Pemasaran (PT Rajagrafindo Persada, 2013)

25. P.W. Hapsari, S.M. Manurung, P. Andam, Wahana, 1 (2016) 